\title{
Surveillance \& Society Introduction: Surveillance and the COVID-19
Pandemic: Views from Around the World
} Dialogue

\section{Bryce Clayton Newell}

\author{
University of Oregon, USA
}

bcnewell@uoregon.edu

Over the past year, the COVID-19 pandemic has dramatically altered our world. It has made real the circumstances many of us had only experienced through film (French and Monahan 2020: 1-2), tabletop board games (Z-Man Games 2021), and other entertainment media. Its impact on state and private surveillance practices has also been dramatic, and the pandemic has highlighted the need for and importance of surveillance studies research that speaks to issues of surveillance in times of crisis. In an editorial in this journal one year ago, French and Monahan (2020: 1) framed "epidemics, pandemics, and outbreaks as social problems" and urged surveillance studies researchers to "attend to [the] cultural, symbolic, structural, and complex material dimensions" of these events, and "to keep track of how these terms contain and configure bodily vulnerability, stigmatization and marginalization, structural inequalities and violence, and disease construction and management." Within a relatively short time, scholars have already begun to address this need (see, e.g., Lambert and Henry 2020; Taylor et al. 2020a; Milan, Treré, and Masiero 2021). With the world in chaos and lockdown, research itself has become more difficult for many (and, importantly, burdens have not been shared equally or equitably), but the need to understand, examine, and critique institutional, surveillance-driven responses to the COVID-19 pandemic remains.

The pandemic, and the array of state and corporate surveillance initiatives that grew up quickly in the early months of 2020, marked an "epidemiological turn in digital surveillance" (Taylor et al. 2020b: 11), bringing public health and disease surveillance programs into direct connection with the sorts of social, data-driven surveillance concerns typically addressed in surveillance studies research. Framed differently, the contrast (and confluence) is between "surveillance of disease" and "surveillance of individuals" (French and Monahan 2020: 4). One of the earliest examples of pandemic-related surveillance proposals was COVID19 contract-tracing proximity apps - smartphone apps with the potential to alert users and authorities when a user's phone had come into close proximity with a COVID-19-positive person. While some public health researchers argued that technologies like proximity apps could "act as a force multiplier" (Watson et al. 2020) in important contract-tracing programs, others focused on the privacy and surveillance-related implications of these schemes - with some proposing best practices to preserve civil liberties (see, e.g., Schwartz 2020; Crocker, Opsahl, and Cyphers 2020). As argued by the Electronic Frontier Foundation, "we cannot solve a pandemic by coding the perfect app" (Crocker, Opsahl, and Cyphers 2020).

On one hand, this might be viewed as a moment for conceptualizing COVID-19-related surveillance of persons as a mechanism of care (see, e.g., Stoddart 2014; Walsh 2010; Newell, Gomez, and Guajardo 2017: 33). We might see surveillance as a justified, ethical response to a pressing social problem (see the compelling framework presented by Macnish [2014], applying just war theory to questions about the ethics of surveillance). On the other hand, we might see this moment characterized by the global corporate technology sector's efforts to mobilize, seize power, and benefit commercially from the extraction of 
additional data from users' digital devices (Taylor et al. 2020b: 9, 11). Similarly, we have seen "politicians... using the pandemic to, in some cases radically, redistribute power to serve their interests" (McDonald 2020: 21). Different communities also have different needs and histories with surveillance, and one-size-fits-all surveillance programs may not always serve the interests of many communities. For example, Lambert and Henry (2020: 422) point to the potential for pandemic-related surveillance to empower native and indigenous communities, but caution that ill-advised surveillance programs may only exacerbate problems of colonization and domination, leading to "unethical, ineffective, and inefficient pandemic responses."

This Dialogue section contributes to the ongoing scholarly discussion about how the pandemic has affected surveillance practices around the world. The six contributions included here join a rapidly expanding scholarly literature, including two recent open-access books on the implications of surveillance and datafication for those living "at the margins" of society (Milan, Treré, and Masiero 2021) and the role that the surveillance, data, and the global technology industry have played in responses to the pandemic around the world (Taylor et al. 2020a). The contributors to this section were asked to consider how the global COVID-19 pandemic has affected state or private surveillance around the world during the course of the past year, whether new forms of surveillance emerged, and, if so, how these new surveillance systems fit into or break out of existing models or theories of surveillance in society. From their research, we find a variety of approaches to understanding and critiquing the use and adaptation of surveillance in times of global public health crisis.

First, Marciano (2021) examines the Israeli government's rapid response to the World Health Organization's declaration of the COVID-19 pandemic in March 2020, with a focus on the securitization and militarization of their response. Just days after the WHO's declaration, Prime Minister Benjamin Netanyahu and the Israeli parliament quickly gave the Israel Security Agency the authority and charge "to track citizens' geolocations to slow the spread of the virus." As Marciano explains, the Israeli government framed the pandemic in militaristic terms - as a war that must be won, a battle that must be fought. Marciano also argues that the security-focused surveillance in response to the pandemic "constitutes a turning point for Israel, both in its formation as a surveillance society and in revalidating its security-oriented, militaristic tendencies." Despite the fact that "the wide distribution of CCTV cameras in public areas characteristic of Western surveillance societies was never part of Israel's surveillance agenda," the country had taken steps in recent years toward becoming a surveillance society. The COVID-19 pandemic, Marciano argues, "was too challenging and tempting, or it was what Israel needed to put its democratic foundations to the test and redefine its surveillance agenda."

Second, Liu (2021) provides the first of two China-focused pieces in this issue. As the perceived center of the initial coronavirus outbreak, China's response has been monitored closely over the past year. Liu focuses attention on the "Health Code" app - a proximity and contract-tracing app launched in February 2020 as a collaboration between technology companies and municipal governments within China-but situates this app within the broader surveillance response. Much of Liu's piece examines how Chinese residents perceive of China's surveillance during the pandemic as compared to Western countries, drawing on interviews and analysis of social media posts on Weibo. Outlining three stages in the global coronavirus pandemic response, Liu argues that Chinese citizens often apologized for China's surveillance efforts while criticizing Western surveillance practices (such as the United States' National Security Agency's mass surveillance programs) and Western criticism of China. In contrast to a slow and contradictory response to the pandemic in the United States, as prominently reported in China, "surveillance in China became evidence of a caring government that respects science." While recognizing that "Chinese propaganda and censorship contribute to this public antagonism towards the West," Lui argues that we should not "ignore the spontaneity and complicated social context that produces" such public opinions.

Third, Siqueira Cassiano, Haggerty, and Bernot (2021) also examine China's response. The authors explain how the Chinese government's reaction in the early days of the COVID-19 pandemic was an enthusiastic turn "to 'smart' surveillance technologies" that "often manifest as extremely localized efforts to regulate 
geographic mobility, social interactions, and health status." However, the information generated by this surveillance ecosystem was not only used as a top-down government tool for controlling citizens and their movements. As Siqueira Cassiano, Haggerty, and Bernot argue, these systems also allowed the government to provide important information to the citizenry, generating "a form of circumscribed individual autonomy." The authors, like Liu (2021), focus on the "quick response health code" app and its abilities and implications. The amount of information consumed and analyzed by the app "would be [in the Western context] akin to combining all of the data held by Facebook, Instagram, Twitter, Tinder, WhatsApp, etc. into a single platform along with all of the information contained by government organizations." Because the data analysis conducted within the app's ecosystem can provide users with a wealth of information, the authors argue that this use of surveillance provides more autonomy to Chinese citizens and residents than Chinese surveillance projects of the past.

Fourth, Akbari (2021) contrasts the surveillance-related response to the pandemic in China with that of Iran. Despite an "unsettling history of control and surveillance" within a country that has often imitated the oppressive surveillance tactics of China and Russia, Akbari finds that the Iranian response to the pandemic was extremely limited. Forms of surveillance evoked by the government in response to popular uprisings, even in the months just prior to the initial coronavirus outbreak, were not used in the country's response to the pandemic. As Akbari notes, "Iran showed no interest in extending its notorious political surveillance practices into the public health arena," perhaps for reasons related to problems of regime trust and legitimacy and technological infrastructure. Drawing on this lack of surveillance response, Akbari provides a critique of how the term "authoritarian surveillance" has been used in academic scholarship, making the case that scholars should develop a more "situated understanding of authoritarian surveillance contextualised within social, political, economic, and historical interrelations."

Fifth, Martin (2021) looks at how times of crisis may legitimize the development and use of digital identity systems, especially in the global South and within the development context. Using India's Aadhaar system as an example ("the world's largest biometric identity system"), Martin argues that the development community should support and invest in the development of data protection regulatory capacity within the countries in which they support digital identity projects. Martin charts the emergence of critical scholarship on digital identities and governance after the 9/11 attacks in the United States and its transformationthrough a "developmental turn in digital identity" - from focusing on state security to "seemingly softer, more humane concerns such as the promotion of human development and social and economic inclusion, particularly for the marginalized." As Martin argues, "the COVID-19 pandemic has provided advocates of digital identity with a new crisis through which to promote and legitimize identification systems, particularly in low- and middle-income countries," including through calls to develop "an open-source platform... colloquially referred to as "Aadhaar in a box'." In conclusion, Martin argues that surveillance studies scholars need to critically assess the development community's shift toward providing open-source, ready solutions to digital identity systems to the Global South.

Finally, Trottier, Huang, and Gabdulhakov (2021) take us in another direction. The authors examine government and civilian responses to anti-social pandemic behavior by members of their communitiesreferring to those who engage in such behavior as "covidiots." These problematic behaviors include "hoarding supplies, not wearing a mask, and travelling or congregating in public." Trottier, Huang, and Gabdulhakov provide examples of state-supported calls for citizens to report these transgressive behaviors, the news media's promotion of lateral scrutiny, and purely private civilian responses that often take shape on internet platforms like Reddit and Twitter. Importantly, they make the case for seeing these pandemicrelated responses as part of a broader trend toward increased lateral surveillance and of the "merging of public health surveillance, urban security, workplace surveillance, as well as the most mundane and intimate forms of lateral surveillance." The authors provide an interesting look at how these practices have taken shape in the Netherlands, several post-Soviet Central Asian states, and China.

These short Dialogue pieces provide only a small glimpse into how the COVID-19 pandemic has affected surveillance practices in countries around the world. Importantly, we are beginning to see researchers from 
a variety of backgrounds address these important questions. Besides understanding the direct consequences of the global pandemic response, including a general turn toward more expansive surveillance during times of crisis, surveillance studies scholars must continue watching, ready to investigate what these developments mean for the post-pandemic world.

\section{References}

Akbari, Azadeh. 2021. Authoritarian Surveillance: A Corona Test. Surveillance \& Society 19 (1): 98-103.

Crocker, Andrew, Kurt Opsahl, and Bennett Cyphers. 2020. The Challenge of Proximity Apps For COVID-19 Contact Tracing. Electronic Frontier Foundation, April 10. https:/www.eff.org/deeplinks/2020/04/challenge-proximity-apps-covid-19contact-tracing [accessed February 15, 2021].

French, Martin, and Torin Monahan. 2020. Dis-ease Surveillance: How Might Surveillance Studies Address COVID-19? Surveillance \& Society 18 (1): 1-11.

Lambert, Simon, and Robert Henry. 2020. Surveilling Indigenous Communities in a Time of Pandemic. Surveillance \& Society 18 (3): $422-425$.

Liu, Chuncheng. 2021. Chinese Public's Support for Covid-19 Surveillance in Relation to the West. Surveillance \& Society 19 (1): 89-93.

Macnish, Kevin. 2014. Just Surveillance: Towards a Normative Theory of Surveillance. Surveillance \& Society 12 (1): $142-153$.

Marciano, Avi. 2021. Israel's Mass Surveillance During Covid-19: A Missed Opportunity. Surveillance \& Society 19 (1): 85-88.

Martin, Aaron. 2021. Aadhaar in a Box?: Legitimizing Digital Identity in Times of Crisis. Surveillance \& Society 19 (1): $104-108$.

McDonald, Sean Martin. 2020. Technology Theatre and Seizure. In Data Justice and COVID-19: Global Perspectives, edited by Linnet Taylor, Gargi Sharma, Aaron Martin, and Shazade Jameson, 20-27. London: Meatspace Press.

Milan, Stefania, Emiliano Treré, and Silvia Masiero, eds. 2021. COVID-19 from the Margins: Pandemic Invisibilities, Policies and Resistance in the Datafied Society. Amsterdam, NL: Institute of Network Cultures.

Newell, Bryce Clayton, Ricardo Gomez, and Verónica E. Guajardo. 2017. Sensors, Cameras, and the New "Normal" in Clandestine Migration: How Undocumented Migrants Experience Surveillance at the U.S.-Mexico Border. Surveillance \& Society 15 (1): 21-41.

Schwartz, Paul. 2020. Protecting Privacy on COVID-19 Surveillance Apps. IAPP.org, May 18. https://iapp.org/news/a/protectingprivacy-on-covid-surveillance-apps/ [accessed February 15, 2021].

Siqueira Cassiano, Marcella, Kevin D. Haggerty, and Ausma Bernot. 2021. China's Response to the Covid-19 Pandemic: Surveillance and Autonomy. Surveillance \& Society 19 (1): 94-97.

Stoddart, Eric. 2014. A Surveillance of Care: Evaluating Surveillance Ethically. In Routledge Handbook of Surveillance Studies, edited by Kirstie Ball, Kevin D. Haggerty, and David Lyon, 369-376. New York: Routledge.

Taylor, Linnet, Gargi Sharma, Aaron Martin, and Shazade Jameson, eds. 2020a. Data Justice and COVID-19: Global Perspectives. London: Meatspace Press.

Taylor, Linnet, Gargi Sharma, Aaron Martin, and Shazade Jameson. 2020b. What Does the COVID-19 Response Mean for Global Data Justice? In Data Justice and COVID-19: Global Perspectives, edited by Linnet Taylor, Gargi Sharma, Aaron Martin, and Shazade Jameson, 8-17. London: Meatspace Press.

Trottier, Daniel, Qian Huang, and Rashid Gabdulhakov. 2021. Covidiots as Global Acceleration of Local Surveillance Practices. Surveillance \& Society 19 (1): 109-113.

Walsh, James P. 2010. From Border Control to Border Care: The Political and Ethical Potential of Surveillance. Surveillance \& Society 8 (2): 113-130.

Watson, Crystal, Anita Cicero, James Blumenstock, and Michael Fraser. 2020. A National Plan to Enable Comprehensive COVID19 Case Finding and Contact Tracing in the US. Johns Hopkins Center for Health Security, April 10. https://www.centerforhealthsecurity.org/our-work/pubs_archive/pubs-pdfs/2020/200410-national-plan-to-contacttracing.pdf [accessed February 15, 2021].

Z-Man Games. 2021. Pandemic Games and Expansions. https://www.zmangames.com/en/games/pandemic/ [accessed February 15, 2021]. 